\title{
Disentangling succession and entrepreneurship gender gaps: gender norms, culture, and family
}

\author{
Manuel Feldmann • Martin Lukes • Lorraine Uhlaner
}

Accepted: 30 September 2020 / Published online: 21 November 2020

(C) The Author(s) 2020

\begin{abstract}
This study adapts a multi-level view of culture, including society- and family-based gender norms and the family embeddedness perspective, to predict the career status of a sample of 2897 young Europeans (aged 18-35) from 11 countries, with at least one selfemployed parent. We find that gender identity is associated with career status such that a woman is more likely than a man to be an employee vs. a successor to a family firm but no less likely to be a founder as compared with either being an employee or successor. However, certain family and society-level culture variables combined with gender identity reverse these trends. A woman with caring responsibilities is more likely to be a successor than either a founder or employee. Also, while two-way interaction effects for traditional gender norms and having a self-employed mother are weak or not significant, the study finds that in combination, a woman reporting both traditional gender norms
\end{abstract}

M. Feldmann $(\bowtie)$

Faculty of Economics and Social Sciences, University of Heidelberg, Bergheimer Str. 58, 69115 Heidelberg, Germany e-mail: manuel.m.feldmann@gmail.com

\section{Lukes}

Department of Entrepreneurship, Prague University of Economics and Business, nam. W. Churchilla 4, 13067 Prague 3,

Czech Republic

e-mail: martin.lukes@vse.cz

L. Uhlaner

Department of Management and Humanities, EDHEC Business

School, 24, Avenue Gustave Delory_CS 50411, 59057 Roubaix

Cedex 1, France

e-mail: uhlaner@gmail.com and having a self-employed mother is more likely to be a successor than being either an employee or a founder, reversing gender identity main effects. Incorporating the family embeddedness perspective and the role of culture in occupational choice, we develop a better view of the gender gap in entrepreneurship, finding that the family may serve as a stronger influence than society when implied norms of these two levels of culture clash. By examining actual rather than intended career choice, we also contribute to the occupational choice literature on youth employment.

Keywords Entrepreneurship · Family embeddedness . Gender Culture $\cdot$ Family business succession $\cdot$ Selfemployment

JEL classifications $\mathrm{C} 12 \cdot \mathrm{C} 31 \cdot \mathrm{C} 83 \cdot \mathrm{J} 12 \cdot \mathrm{J} 16 \cdot \mathrm{J} 24$. $\mathrm{L} 26 \cdot \mathrm{M} 13 \cdot \mathrm{M} 14$

\section{Introduction}

An individual's involvement in an entrepreneurial career, whether as a founder or family business successor, is not gender neutral (Ahl 2006; Jennings and Brush 2013), with men's entrepreneurial activity higher than that of women in most countries (Baughn et al. 2006; Jennings and Brush 2013; Lukeš et al. 2019). Furthermore, daughters in families with self-employed parents are less likely than sons to take over the family business (Nelson and Constantinidis 2017; Overbeke et al. 2013). Jennings and Brush (2013, p. 679) sum up these 
findings by suggesting that "entrepreneurship is a gendered phenomenon."

To explain gender effects, studies typically conclude that gender is primarily socially constructed rather than biologically determined, and thus heavily influenced by cultural factors and differences within and across societies (Elam and Terjesen 2010; Kubíček and Machek 2019; Overbeke et al. 2013). Hence, gender identity (whether one describes and perceives oneself as a man, woman, or other; Diamond 2002) and gender norms (i.e. personal beliefs about how men vs. women are supposed to behave; Pearse and Connell 2016) may help to explain occupational choices including starting one's own firm or joining the family firm (Greene et al. 2013; Storey and Greene 2010). Although non-identification with binary gender choices (e.g. male vs. female) is being increasingly recognised (Marlow and Martinez Dy 2018), the often implicit gender norms derived from one's culture, and manifested through one's gender identity, remain a strong influence on behaviour (Elam and Terjesen 2010).

Building on Leung et al.'s (2005) model of culture, Bullough et al. (2017b) suggest that the meaning of gender for each individual derives from multiple levels of one's cultural environment (Bullough et al. 2017b; Leung et al. 2005). From birth onwards, individuals receive signals from their surroundings, both consciously and unconsciously, thereby acquiring their own perception of what it means to be a man or a woman. Gender identity, in turn, directly influences the worklife decisions that young people make (Baughn et al. 2006; Bullough et al. 2017b).

In spite of the recognition that gender is socially constructed, our understanding of which levels of culture are most influential in determining occupational choice, and how these levels may interact with one's gender identity, remains inadequate. Our overall research question is thus whether gender identity interacts with traditional gender norms and family relationships, including care obligations of a family member and the presence of a self-employed mother, to influence the career choices of young men and women. To better understand the influence of the family, we draw on the family embeddedness perspective of entrepreneurship (Aldrich and Cliff 2003; Azmat and Fujimoto 2016), together with role modelling concepts derived from social learning theory (Bloemen-Bekx et al. 2019).

The data in our study draws on a subsample of 2897 young adults (aged 18-35), having at least one self- employed parent, from 11 countries and from the Cultural Pathways of Economic Self-Sufficiency and Entrepreneurship (CUPESSE) project. This dataset allows us to compare the occupational choices of young working adults between family business successors, business founders, and paid employees. Our results suggest that when norms clash, family may play a stronger role than societal norms due to higher proximity, longevity, and intensity of family relationships. Family obligations, i.e. caring for a child or other family member, can also push young women toward family business succession ( $\mathrm{v}$ paid employment or founding). Moreover, we see that a gender gap in our sample of young Europeans with self-employed parents can only be identified among successors, but not among independent founders.

\section{Theoretical foundations}

\subsection{Culture, gender, and entrepreneurship}

House et al. (2002, p. 15) define culture as "shared motives, values, beliefs, identities and interpretations or meanings of significant events that result from common experiences of members or collectives that are transmitted across generations." Culture can be transmitted by observed artefacts and behaviours, shared values, or at the deepest level, basic assumptions which are invisible and are taken for granted (Leung et al. 2005). Thus, gender norms can be viewed as essential aspects of culture. While one's gender identity and gender norms likely derive from several sources, society-at-large probably serves as a pervasive "background" influence (Elam and Terjesen 2010). A daughter may resist taking over a parent's business in construction because it is perceived as a male-dominated industry, and thus viewed by her as an inappropriate career choice. Schröder et al. (2011) found that daughters more commonly preferred to start their own firms rather than join the family firm in a male-dominated industry.

However, as pointed out by Leung et al. (2005), culture consists of several levels below and above the societal level, which may influence each person's social identity. Research on gender and entrepreneurship among youths and young adults recognises that the family transmits cultural norms and values (Bullough et al. 2017b; Nelson and Constantinidis 2017). More specifically, the family embeddedness perspective is 
that people "are not atomised decision-makers", but instead connected "in networks of social relations" (Aldrich and Cliff 2003: 577), the family being the closest and possibly strongest network. The creation of a new business is influenced by an individual's family-related roles and responsibilities (Aldrich and Cliff 2003; Jennings and Brush 2013). Aldrich and Cliff (2003, p. 573) argue, therefore, that family and entrepreneurship must be studied as "inextricably intertwined."

In our study, we first consider the main effect of gender identity on occupational choice among young people. In spite of increased female participation in the labour market, family business succession in particular remains a male-dominated domain (Kubíček and Machek 2019), with fathers often preferring sons over daughters (Ahl 2006; Campopiano et al. 2017; Rothausen 2009; Schröder et al. 2011) and giving daughters more subordinate, less powerful, and less visible roles (Karataş-Özkan et al. 2011). In many families, the primogeniture rule, i.e. that the eldest son inherits the family business, augments this tendency even further (Nelson and Constantinidis 2017; Overbeke et al. 2013). Daughters are often only considered when no sons are available (Nelson and Constantinidis 2017) or later in their lives when a family or business crisis occurs (Overbeke et al. 2013).

Empirical research comparing paid employment with both independent self-employment and family business succession focuses primarily on entrepreneurial intention (e.g. Zellweger et al. 2011) but reaffirms the preference of daughters for paid employment over family business succession. In sum, we hypothesise in line with prior research that compared with both paid employment and founding an independent firm, women are less likely to be a successor to the family business of one or both parents. We thus posit:

Hypothesis 1. Gender identity is associated with the career status of young people such that a woman is more likely than a man to be:

a) an employee than a successor; and

b) a founder than a successor.

\subsection{Traditional gender norms as moderator}

Next, we consider whether the individual's own gender norms interact with his or her gender identity to influence career choice. These norms may derive from the national culture (Elam and Terjesen 2010) or more directly from the young adult's family members, and thus may vary among individuals within the same larger society. While culture at the global level is shifting toward more gender equality, in many societies, women are still defined primarily through traditional gender norms - that men should be responsible for making money and women for looking after home and family (Bullough et al. 2017a; Greene et al. 2013). Traditional gender norms may not only reduce the likelihood that daughters will be considered successors by their parents but also blind daughters to the opportunity of a succession career path. Not seeing an open opportunity within the family firm, career-seeking daughters may choose employment outside the family firm or independent selfemployment. Being blinded to succession possibilities in this way may make them more apt to accept genderrelated expectations (Hytti et al. 2016) and simultaneously make them invisible to parents as contenders for succession. We thus posit:

Hypothesis 2. Traditional gender norms moderate the relationship between gender identity and career status such that a woman who adheres more to traditional gender norms is even more likely than a woman who adheres less to traditional gender norms to be:

a) an employee than a successor; and

b) a founder than a successor.

\subsection{Caring for a family member as moderator}

Drawing on the family embeddedness perspective, the next two hypotheses consider how certain family relationships may affect entrepreneurial career choices. We consider first how care responsibilities in the household may moderate the effect of gender identity on career choice. Work-life balance and job flexibility can be important factors in the decision-making of young adults when having to combine work with childcare (Jennings and Brush 2013). This connection may be stronger where women are expected to perform the main responsibilities for childcare and the household (Azmat and Fujimoto 2016; Elam and Terjesen 2010). Inflexibility of paid employment often impairs women's opportunities in the labour market (Baughn et al. 2006). 
Past research argues that young women requiring increased levels of schedule flexibility may seek selfemployment (Baughn et al. 2006; Greene et al. 2013; Wellington 2006), particularly when public day care is not easily accessible (Ahl 2006) and they have children at home (Noseleit 2014). Many more self-employed women than self-employed men work part-time (Marlow and McAdam 2013), suggesting that women combine self-employment with other duties such as family and household care.

Nonetheless, launching and expanding a new venture requires substantial time investments combined with high risks and failure rates. This becomes an especially important issue when there is a simultaneous need to care for the family (Wellington 2006). In contrast, a family business run by a young woman's parents represents less risk: it is already established in the market, backed up by substantial know-how and management capabilities. Parents may also provide childcare support (Storey and Greene 2010), thereby increasing workfamily balance. In conclusion, self-employment can be a chance to combine work and family for young women, albeit not without risks - family business succession may mitigate some of those risks and provide enhanced flexibility and support to young mothers. We thus posit:

Hypothesis 3. Caring responsibilities moderate the relationship between gender identity and career status such that a woman with caring responsibilities is more likely than a woman without caring responsibilities to be:

a) a successor than an employee; and

b) a successor than a founder.

\subsection{Mother's self-employment as moderator}

Parental self-employment has been shown to be the strongest determinant of entrepreneurial engagement in the next generation (Lindquist et al. 2015; Markussen and Røed 2017). Many recent studies identify role modelling as the strongest mechanism in intergenerational transmission (Lindquist et al. 2015). Children living in an entrepreneurial family observe their parents' work on an everyday basis, help them after school or during holidays, and become familiar with what it means to be an entrepreneur (Bloemen-Bekx et al. 2019). In so doing, they internalise entrepreneurial values and norms. Role modelling is an integral part of the family embeddedness perspective: it links the changing roles of family members, e.g. mothers, to the different entrepreneurial phenomena in the new venture process, in particular new enterprise formation (Aldrich and Cliff 2003). Moreover, a mother's self-employment is likely to reflect family norms accepting of entrepreneurial women.

Furthermore, studies using various methods (crosssectional, longitudinal, and adoption panels) consistently show that entrepreneurial role models work best along gender lines (Lindquist et al. 2015; Markussen and Røed 2017; Schröder et al. 2011). Sons are more influenced by fathers' self-employment and daughters by their mothers' self-employment because they tend to spend more time with the parent of the same sex, share more of their attributes and learn better from them (Hoffmann et al. 2015).

We further suggest that self-employed mothers have an even greater impact on the propensity of daughters to succeed in the family business for other reasons. First, the self-employed mother may be more likely to operate in an industry that is not male-dominated (Schröder et al. 2011) and therefore offer a career opportunity more appealing to the daughter than to the son (Aldrich and Cliff 2003). Second, the (formerly) self-employed mother less likely holds traditional gender norms, and thus may have a counter-stereotypical influence on daughters (Greene et al. 2013) or already have broken said norms (Bullough et al. 2017b). Self-employed mothers may transmit the credibility and role model of the entrepreneurial woman and greater selfconfidence to their daughters (Campopiano et al. 2017). Finally, with respect to succession vs. founding a firm, if the mother is self-employed, she is likely to be more open to considering a daughter as successor, since women are already accepted as owners in the business. We thus posit:

Hypothesis 4. Having a self-employed mother moderates the relationship between gender identity and career status such that a woman with a selfemployed mother is more likely than a woman without a self-employed mother to be:

a) a successor than an employee; and

b) a successor than a founder. 
2.5 Combined social influences as moderators: mother's self-employment and traditional gender norms

In our final hypothesis, we consider possible outcomes for the effects of gender when different levels of culture may work in opposite directions: traditional gender norms are likely to push women away from family business succession, whereas a self-employed mother does the opposite. We have argued that both gender identity and traditional gender norms derive from societal norms. By contrast, having a self-employed mother may reflect family values and norms which more directly encourage the young adult to choose family business succession. What can we expect to happen when these two levels of culture represent contradictory cues? The family embeddedness perspective recognises that such contrasts may arise, and depending on the values espoused at the family level, they may enable or prevent entrepreneurship from taking place (Azmat and Fujimoto 2016). In a study of Afghan and American women, Bullough et al. (2017b) even argue that the family as the immediate group is likely to have a stronger influence on the woman's behaviour than society at large. Afghan female entrepreneurs further indicated that it becomes easier for other female family members to follow in the footsteps of women who have already broken gender norms, including by starting their own businesses. Focusing on work groups, Leung et al. (2005) note a weaker effect of societal norms in contrast with in-group norms, based on proximity, longevity, and intensity of ties. Applying these same criteria to the family as in-group, we argue family will have a stronger influence than societal norms. Furthermore, where the mother is self-employed, but also the primary care giver, she acts as a role model especially for the daughter by combining work and family effectively. Either way, we expect women to be more closely influenced by their mothers' occupational status (especially if the mother is self-employed), in spite of holding more traditional gender norms. We thus posit:

Hypothesis 5. The moderating effect of traditional gender norms on the relationship between gender identity and career status predicted in Hypothesis 2 will be reversed when the mother has been selfemployed, such that a woman who adheres more to traditional gender norms is more likely than a woman who adheres less to traditional gender norms to be:

a) a successor than an employee; and

b) a successor than a founder.

\section{Method}

\subsection{Data}

We base our analysis on data collected from the CUPESSE project between January and June 2016 in 11 European countries (see Table 1). For the main study, each country provided stratified random samples of at least 1000 youths aged 18 to 35 (Tosun et al. 2019). From this larger dataset with 20,008 respondents, we based our study on a subsample of 2897 respondents meeting four criteria: (1) having at least one previously or currently elf-employed parent; (2) being active in the labour market (employees and the self-employed); (3) not reporting a combination of both self-employment and paid employment; and (4) for the self-employed respondents, explicitly saying that they either founded a company or entered the family business.

Table 1 presents a detailed description of the sample for each country. Turkey shows much lower participation rates in the labour market among women. Moreover, for the total sample, $47.5 \%$ of paid employees, $41.0 \%$ of founders, and $27.3 \%$ of successors are women. Excluding Turkish respondents, the gender gap vanishes between paid employees $(50.6 \%)$ and founders (49.14\%) but persists for successors (only $37.5 \%$ being women). Hence, while we include respondents from Turkey in the main analyses, we also calculate a robustness test, retesting hypotheses without Turkey.

\subsection{Measures}

\subsubsection{Dependent variable: career status}

Our dependent variable Career status is a categorical variable with three dimensions: Employee, Founder, and Successor. Those respondents reporting their career status as "in paid work" were coded as an employee. Those indicating they were "self-employed" were then asked how they started their business. Those answering "founded a company" were classified as founder and those who "entered the family business" were classified as successor.

\subsubsection{Independent and moderator variables}

Gender identity is represented by a self-reported binary variable taking the value of 1 if the respondent reported being female and 0 if the respondent 
Table 1 Sample description and demographics by gender

\begin{tabular}{|c|c|c|c|c|c|c|}
\hline Country & $N$ & Women & Mean age women & Mean age men & $\begin{array}{l}\text { Median education } \\
\text { women }\end{array}$ & $\begin{array}{l}\text { Median education } \\
\text { men }\end{array}$ \\
\hline Austria & 215 & $46.2 \%$ & 27.07 & 27.15 & 5 & 5 \\
\hline Czech Rep. & 187 & $45.3 \%$ & 28.19 & 28.52 & 6 & 3 \\
\hline Denmark & 93 & $43.3 \%$ & 28.98 & 29.25 & 5 & 5 \\
\hline Germany & 424 & $49.5 \%$ & 27.30 & 28.04 & 5 & 5 \\
\hline Greece & 365 & $55.8 \%$ & 29.68 & 30.12 & 6 & 6 \\
\hline Hungary & 70 & $48.4 \%$ & 27.88 & 27.89 & 5 & 3 \\
\hline Italy & 142 & $42.8 \%$ & 28.29 & 28.31 & 6 & 6 \\
\hline Spain & 237 & $51.6 \%$ & 29.29 & 29.49 & 6 & 5 \\
\hline Switzerland & 155 & $48.2 \%$ & 26.99 & 28.76 & 5 & 7 \\
\hline Turkey & 501 & $22.1 \%^{\mathrm{a}}$ & 26.54 & 27.20 & 4 & 4 \\
\hline UK & 508 & $60.0 \%$ & 27.60 & 28.65 & 6 & 6 \\
\hline Total & 2897 & $44.7 \%$ & 27.99 & 28.30 & 5.11 & 4.66 \\
\hline
\end{tabular}

${ }^{\mathrm{a}}$ Females in Turkey are underrepresented in the labour market (see also the discussion on traditional gender norms) and thus more often excluded from the sample (whereas women make up 50\% of the overall Turkish sample)

${ }^{\mathrm{b}}$ ISCED 2011 levels. If still in education, we use the highest level achieved

reported being male. Caring is a binary variable with the value of 1 if the respondent has regular caring responsibilities, whether for a child or other individual. Self-employed (SE) mother is a binary variable that is coded as 1 if the respondent's mother is self-employed or was when the respondent was 14. Respondents where both parents are or were previously self-employed were also coded as 1 , with 0 representing respondents where only the father was self-employed. ${ }^{1}$ Finally, based on the established measurement of gender norms in the International Social Survey Programme (Braun and Scott 2009), we measure Traditional gender norms on a 4-point scale (from 1 = "Strongly disagree" to $4=$ "Strongly agree"), capturing respondents' agreement with the statement "A man's job is to earn money; a woman's job is to look after the home and family." Since it is a quasi-continuous variable, we centred Traditional gender norms around its grand mean and standardised it.

\footnotetext{
1 'Self-employed father only' is the reference category since we were interested in all cases where the respondent's mother was or is selfemployed, either with or without a self-employed father. $62.8 \%$ of respondents in our study have a self-employed father only, $19.7 \%$ have two self-employed parents, and $17.5 \%$ have a self-employed mother only.
}

\subsubsection{Control variables}

Respondents were asked their age in years. Age ranges from 18 to 35 in our sample and was centred around its grand mean. The variable Education is given by the respondent's highest level of education achieved at the time of the survey according to the International Standard Classification of Education (ISCED) ${ }^{2}$ of 2011: low ISCED levels ( 1 or 2 ) are coded as -1 , medium ISCED levels (3-5) as 0 and high ISCED levels (>5) as 1. Those still studying part-time are attributed their highest completed level of education. Sibling is a binary indicator that shows whether the respondent has siblings. Minority is a binary indicator that shows whether the respondent reports being part of an ethnic minority. Additionally, we include ten country dummies using Hungary as the reference country since it has the lowest self-employment rate.

\subsubsection{Descriptive statistics}

Table 2 provides an overview of all variables, including their means, standard deviations, and Pearson correlation coefficients. To test for multicollinearity, we calculated Variance Inflation Factors (VIFs) based on an Ordinary Least Squares regression. The maximum value

\footnotetext{
${ }^{2}$ We use the most recent version (November 2011) of the International Standard Classification of Education.
} 
was 1.19 , well below any level indicative of multicollinearity (Hair et al. 2010).

\subsection{Data analysis}

First, in order to sense whether our moderator variables might reflect cultural influences at the national level, we assessed the equality of means across participating countries using separate logistic regressions. The procedure is comparable to analysis of variance for binary and ordinal response data. We relied on a statistically significant Wald Chi-Square as evidence to reject the null hypothesis of equal means across countries.

To test each hypothesis, we first conducted a multinomial logistic regression. According to previous studies (e.g. Schröder et al. 2011; Zellweger et al. 2011), this is a suitable approach for such research designs. Models 1 and 2 use succession as the base category for comparison, while model 3 uses paid employment as the base category, in order to test for transitiveness between the three dimensions.

As several studies have shown, however, the interaction coefficient is not a complete test of the interaction effect (Norton et al. 2004; Plummer et al. 2016). The interaction effect can be significant even if the interaction coefficient is not (KaracaMandic et al. 2012). We hence also calculated average marginal effects based on separate logistic regressions for each outcome and graphed significant interactions with adjusted predictions at meaningful values. The average marginal effects of interaction terms are calculated as cross derivatives (KaracaMandic et al. 2012; cf. Williams 2012). We first tested the interaction hypotheses (H2-H5), checking for the $p$ value of the interaction coefficient in the multinomial logistic regression analysis. If the coefficient was not statistically significant, we examined average marginal effects (AMEs). If either interaction coefficients from the logistic regression analysis or AMEs showed significant $p$ values, we then graphed the interaction to interpret the interaction effect. $^{3}$

\footnotetext{
${ }^{3}$ Since average marginal effects are differently scaled, it is not necessary for both them and the logit coefficients to have precisely the same outcomes (especially with respect to $p$ values).
}

\section{Results}

\subsection{Focal variables across cultures}

Table 3 shows the percentages of men and women with caring responsibilities, self-employed mothers, and the average traditional gender norm score, for each of the countries in the study. The Wald Chi-squared statistic is reported in the table for each column. National differences based on the Wald Chi-squared statistic are statistically significant $(p<.01)$, for all categories tested. These results suggest that underlying differences in individual responses may be at least in part due to national (i.e. society-level) culture.

\subsection{Results of the hypotheses tests}

Table 4 presents the results for the five hypotheses, as well as additional analyses comparing founders and employed individuals. In Table 4, for each model, column $a$ includes the control variables, column $b$ adds the main effects, column $c$ adds the two-way interactions, and column $d$ shows the results of a test for the three-way interaction (H5).

The results of the multinomial logistic regression for Hypothesis 1, shown in columns $1 \mathrm{~b}$ (for H1a) and $2 \mathrm{~b}$ (for $\mathrm{H} 1 \mathrm{~b}$ ), based on a review of the interaction coefficients, are mixed (see Table 4). Women are more likely to select employment over succession in support of H1a ( $\beta=0.586, p<.05)$. However, the choice between founder and successor, shown in column $2 \mathrm{~b}$ (for H1b) is not significant $(\beta=0.432$, ns). Hence, we reject H1b. Average marginal effects further support this conclusion.

We tested $\mathrm{H} 2, \mathrm{H} 3$, and $\mathrm{H} 4$, first by examining the statistical significance of the interaction effects for the multinomial logistic regression (see Table 4, columns $1 \mathrm{c}$ and 2c). Given that the coefficient for neither $\mathrm{H} 2 \mathrm{a}$ nor $\mathrm{H} 2 \mathrm{~b}$ was significant, we reviewed the AMEs (see Table 5). Those results do indicate a trend $(p<.10)$ in the predicted direction for $\mathrm{H} 2 \mathrm{a}$, such that traditional gender norms increase the likelihood of women being employees (AME = $0.025 ; p<.10)$ and decrease the likelihood of their being a successor $(\mathrm{AME}=-0.018 ; p<.10)$. Following our stated protocol, we then graphed the interaction (see Fig. 1). ${ }^{4}$ The graphed probabilities suggest that contrary to our

\footnotetext{
${ }^{4}$ The graphs in each of the figures show adjusted predictions at meaningful values (Williams 2012), i.e. absolute percentages, for each career status, whereas Table 4 reports log odds relative to a base category. Absolute and relative changes may go in opposite directions.
} 


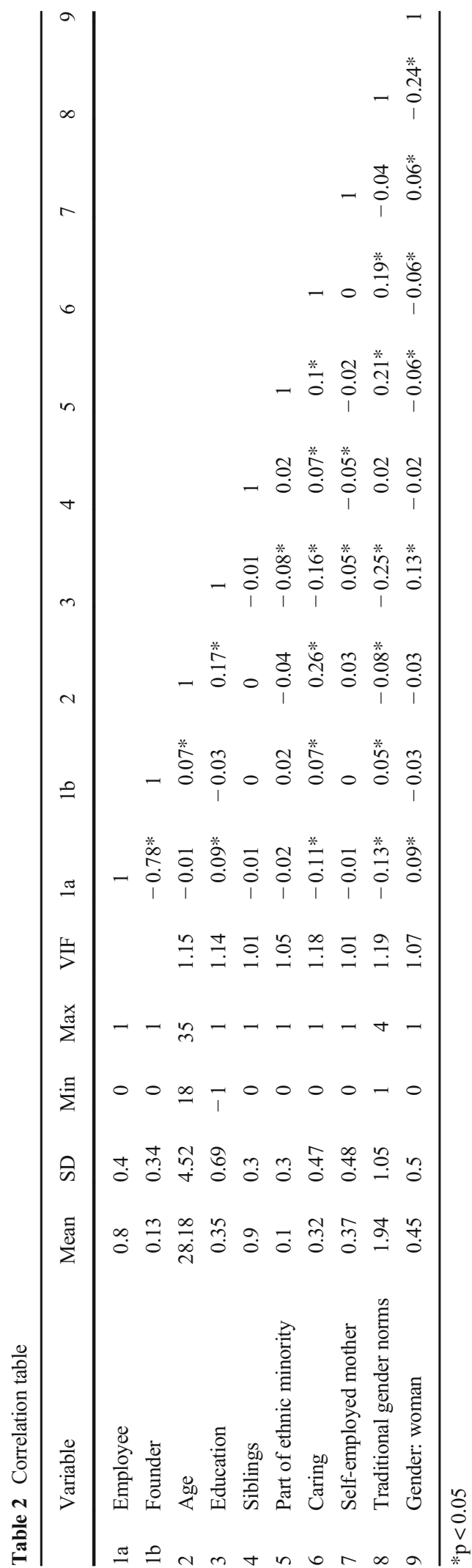

predictions in $\mathrm{H} 2$, traditional gender norms are not directly associated with a greater inclination among women to be employees or founders, but are associated with an increased chance of male succession and founding vs. employment (while women's probabilities remain rather flat). Thus, traditional gender norms increase the gap between the likelihood of men and women being a successor, while Hypothesis $2 \mathrm{~b}$ itself is not supported.

Based on the examination of the coefficients shown in Table 4, our results suggest full support for $\mathrm{H} 3 \mathrm{a}$ and $\mathrm{H} 3 \mathrm{~b}$ : women with caring responsibilities are more likely to be a successor than an employee $(\beta=1.167, p<.001)$ and more likely to be a successor than a founder $(\beta=$ $1.197, p<.01)$. This conclusion is further supported by results for average marginal effects: negative for being an employee $(\mathrm{AME}=-0.034 ; p<.05)$ and positive for being a successor (AME $=0.018 ; p<.10$ ). Figure 2 further illustrates our findings: young women with caring responsibilities are more likely to choose succession and less likely to choose paid employment than those without such responsibilities. The combined graphs suggest that both genders are less likely to be in paid employment when having caring responsibilities while the probabilities of being either a successor or a founder increase, yet the effect for women is much more pronounced, consistent with our predictions for H3ab.

None of the three tests, including results for the regression analysis, average marginal effects and graphical analysis, shown in Tables 4 and 5, supports H4. However, regarding H5, the logistic regression results shown in Table 4, columns $1 \mathrm{~d}$ and $2 \mathrm{~d}$, and which predict a three-way interaction of being a woman, having a selfemployed mother and adhering to traditional gender norms, provide strong support for both $\mathrm{H} 5 \mathrm{a}$, the likelihood of being a successor vs. an employee ( $\beta=-1.052$, $p<.001)$, and $\mathrm{H} 5 \mathrm{~b}$, the likelihood of being a successor vs. a founder increasing for women in the sample $(\beta=-$ $0.616, p<.05)$. Average marginal effects of this interaction mirror these results. Figure 3 illustrates this threeway interaction graphically: traditional gender norms generally increase the probability of being a successor or founder and decrease the probability of being an employee. For women, however, this effect hinges on whether the mother is self-employed. As shown in the figure, we find opposite effects for traditional gender norms for women without a self-employed mother compared with the other three combinations (male with or without an SE mother, female and SE mother), the former tending to be more likely to choose to be an 
Table 3 Bivariate logistic regression results and means of moderator variables across national cultures by gender

\begin{tabular}{|c|c|c|c|c|c|c|}
\hline Country & Caring women & Caring men & SE mother women & SE mother men & TGN women & TGN men \\
\hline Austria & $24.2 \%$ & $25.8 \%$ & $50.5 \%$ & $35.8 \%$ & 1.43 & 1.88 \\
\hline Czech Rep. & $32.2 \%$ & $26.0 \%$ & $34.5 \%$ & $45 \%$ & 1.87 & 2.23 \\
\hline Denmark & $33.3 \%$ & $24.1 \%$ & $41.9 \%$ & $31.5 \%$ & 1.36 & 1.31 \\
\hline Germany & $21.9 \%$ & $20.1 \%$ & $41.0 \%$ & $42.1 \%$ & 1.72 & 1.94 \\
\hline Greece & $35.4 \%$ & $35.2 \%$ & $37.9 \%$ & $45.3 \%$ & 1.49 & 1.98 \\
\hline Hungary & $20.6 \%$ & $22.2 \%$ & $47.1 \%$ & $36.1 \%$ & 1.94 & 2.44 \\
\hline Italy & $20.6 \%$ & $24.1 \%$ & $33.3 \%$ & $49.4 \%$ & 1.75 & 2.04 \\
\hline Spain & $38.2 \%$ & $38.6 \%$ & $48.0 \%$ & $50.0 \%$ & 1.34 & 1.51 \\
\hline Switzerland & $14.3 \%$ & $24.4 \%$ & $40.3 \%$ & $43.6 \%$ & 1.44 & 1.78 \\
\hline Turkey & $35.1 \%$ & $54.5 \%$ & $22.8 \%$ & $11.6 \%$ & 2.50 & 2.90 \\
\hline UK & $27.7 \%$ & $29.9 \%$ & $43.6 \%$ & $38.5 \%$ & 1.61 & 2.02 \\
\hline Mean & $28.5 \%$ & $34.3 \%$ & $40.2 \%$ & $34.6 \%$ & 1.66 & 2.16 \\
\hline SD & 0.452 & 0.343 & 0.491 & 0.476 & 0.912 & 1.101 \\
\hline Wald $\mathrm{Chi}^{2}$ & $29.10^{* *}$ & $105.74 * * *$ & $25.72 * *$ & $114.21 * * *$ & $106.75^{* * *}$ & $232.79 * * *$ \\
\hline
\end{tabular}

$T G N$, traditional gender norm (scaled from 1 = "strongly disagree" over 2 = "somewhat disagree," $3=$ "somewhat agree" to 4 = "strongly agree"). Robust standard errors. For ordinal variables, we conducted an ordinal logistic regression. On the national level, there are 10 degrees of freedom, on the individual level 1,312 for women, 1,585 for men

Note. $* p<.05 ; * * p<.01 ; * * * p<.001$

employee, and less likely to be a founder or successor. Put differently, while traditional gender norms generally drive working women into paid employment, this effect switches toward being self-employed (founder or successor) if the mother is self-employed. These opposite effects for women also help to explain the weak support for $\mathrm{H} 2 \mathrm{a}$ and absence of support for $\mathrm{H} 2 \mathrm{~b}$, which do not take the work status of the mother into account.

\subsection{Other results}

For comparison purposes, although not hypothesised, the last three columns of Table 4 (panel 3) show results for being a founder vs. an employee. It is notable that when family business successors are removed from the overall group of self-employed individuals, there is no significant difference for women in choosing selfemployment (as a founder) over paid employment ( $\beta=-0.136$, ns). The only significant finding linked to the other hypotheses is with regard to Hypothesis 5 . We find a positive three-way interaction effect, suggesting that under the conditions of having a self-employed mother and the respondent leaning toward more traditional gender norms, the female respondent will more likely be a founder than a paid employee.

\subsection{Robustness tests without Turkey}

While a part of Turkey lies geographically in Europe, culturally and economically it is quite distinct from the other countries in our study. Women are underrepresented in the labour market (see Table 1), both men and women are much less likely to have a selfemployed mother, and the average Turkish respondent scores much higher on the traditional gender norm scale (see Table 3). For these reasons we also tested the hypotheses separately without Turkish respondents. ${ }^{5}$ Contrary to the findings for the full sample, we find no support for Hypothesis 1a $(\beta=0.466$, $n s)$, i.e. working women are no more likely than men to report being employees vs. successors. The results for the other hypotheses are consistent with those of the full sample, including statistical support for $\mathrm{H} 3 \mathrm{ab}$ and $\mathrm{H} 5 \mathrm{ab}$, weak support for $\mathrm{H} 2 \mathrm{a}$ (also supported by average marginal effects at the trend level and a graph similar to that of Fig. 1, not reported), and the rejection of $\mathrm{H} 1 \mathrm{~b}, \mathrm{H} 2 \mathrm{~b}$, and $\mathrm{H} 4 \mathrm{ab}$.

\footnotetext{
$\overline{{ }^{5} \text { Results of this }}$ data analysis are available from the corresponding author.
} 


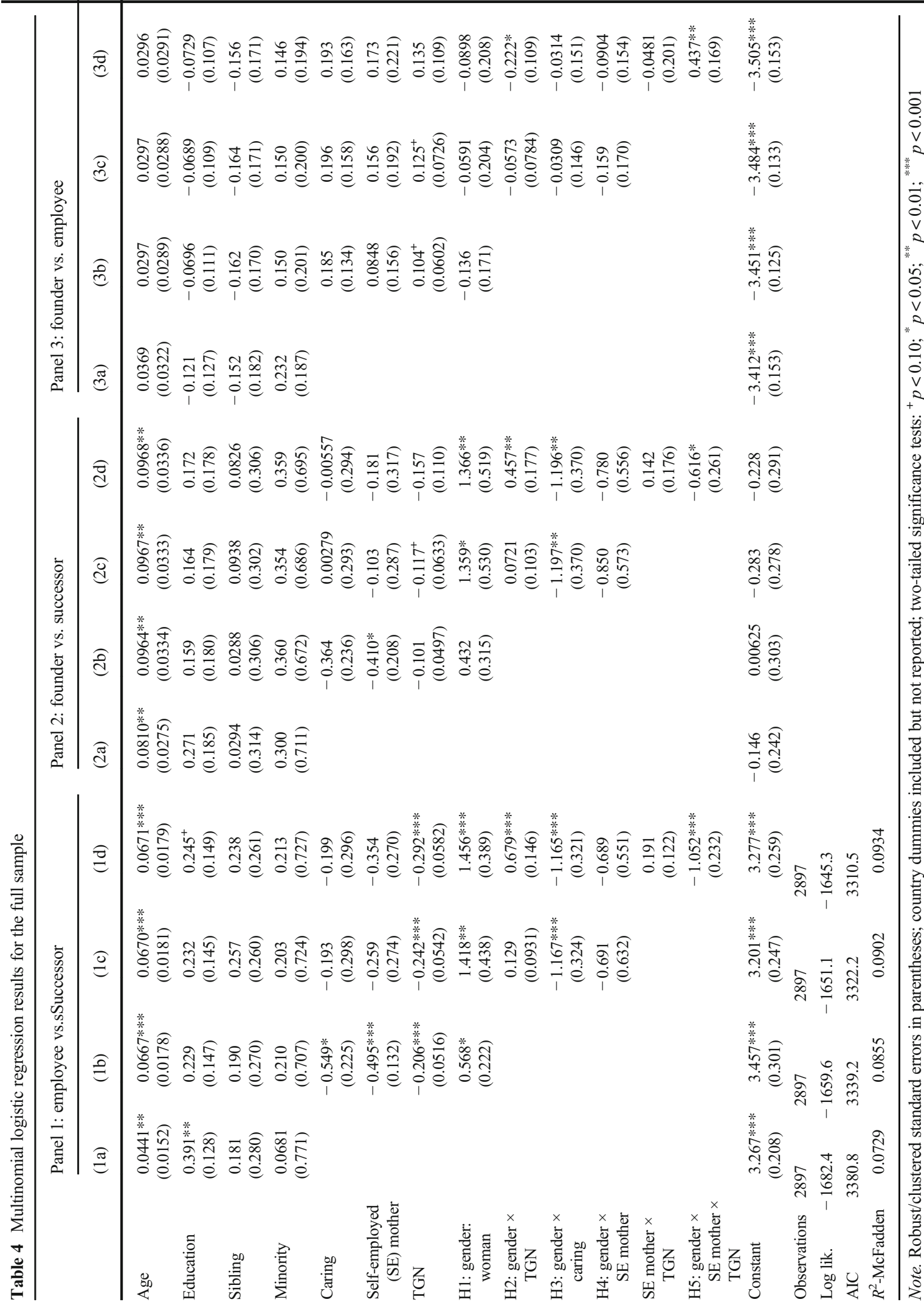


Table 5 Average marginal effects based on separate logistic regressions for the full sample

\begin{tabular}{|c|c|c|c|c|c|c|c|c|c|}
\hline \multirow[b]{3}{*}{ Age } & \multicolumn{3}{|l|}{ Employee } & \multicolumn{3}{|l|}{ Founder } & \multicolumn{3}{|l|}{ Successor } \\
\hline & \multicolumn{3}{|c|}{ Average marginal effects } & \multicolumn{3}{|c|}{ Average marginal effects } & \multicolumn{3}{|c|}{ Average marginal effects } \\
\hline & 0.000 & 0.001 & 0.000 & 0.004 & 0.004 & 0.004 & $-0.004 * *$ & $-0.004 * *$ & $-0.004 * *$ \\
\hline Education & 0.019 & 0.019 & 0.020 & -0.005 & -0.005 & -0.005 & $-0.012^{+}$ & $-0.012^{+}$ & $-0.013^{+}$ \\
\hline Sibling & 0.026 & 0.028 & 0.026 & -0.017 & -0.016 & -0.015 & -0.010 & -0.014 & -0.013 \\
\hline Minority & -0.003 & -0.003 & -0.003 & 0.021 & 0.021 & 0.021 & -0.013 & -0.013 & -0.013 \\
\hline Caring & $-0.046^{+}$ & $-0.046^{*}$ & $-0.046^{*}$ & 0.014 & 0.015 & 0.014 & $0.031^{+}$ & $0.032^{+}$ & $0.032^{+}$ \\
\hline Self-employed (SE) mother & $-0.031 *$ & $-0.031^{+}$ & $-0.031^{*}$ & 0.004 & 0.005 & 0.006 & $0.029 * * *$ & $0.026^{* * *}$ & $0.025 * * *$ \\
\hline TGN & $-0.021 * *$ & $-0.020 * *$ & $-0.018^{*}$ & 0.009 & 0.009 & 0.008 & $0.011 * *$ & $0.011 * *$ & $0.010^{*}$ \\
\hline H1: gender: woman & $0.039^{+}$ & $0.040^{+}$ & $0.043^{+}$ & -0.010 & -0.010 & -0.011 & $-0.030^{+}$ & $-0.031^{+}$ & $-0.033^{+}$ \\
\hline $\mathrm{H} 2:$ gender $\times$ TGN & & $0.025^{+}$ & $0.066 * * *$ & & -0.002 & -0.012 & & $-0.018^{+}$ & $-0.040 *$ \\
\hline H3: gender $\times$ caring & & $-0.034 *$ & $-0.030^{+}$ & & -0.010 & -0.010 & & $0.019^{+}$ & $0.018^{+}$ \\
\hline $\mathrm{H} 4$ : gender $\times \mathrm{SE}$ mother & & 0.001 & -0.002 & & -0.016 & -0.013 & & 0.009 & 0.006 \\
\hline SE mother $\times$ TGN & & & 0.012 & & & -0.001 & & & -0.004 \\
\hline H5: gender $\times$ SE mother $\times$ TGN & & & $-0.090^{*}$ & & & 0.025 & & & $0.028 *$ \\
\hline
\end{tabular}

Note. Country dummies included but not reported. While we show data for all variables, note that we primarily use AME for interpreting the interaction effects, not for main effects

${ }^{+} p<0.10 ;{ }^{*} p<0.05 ;{ }^{* *} p<0.01 ;{ }^{* * *} p<0.001$ - two-tailed significance tests
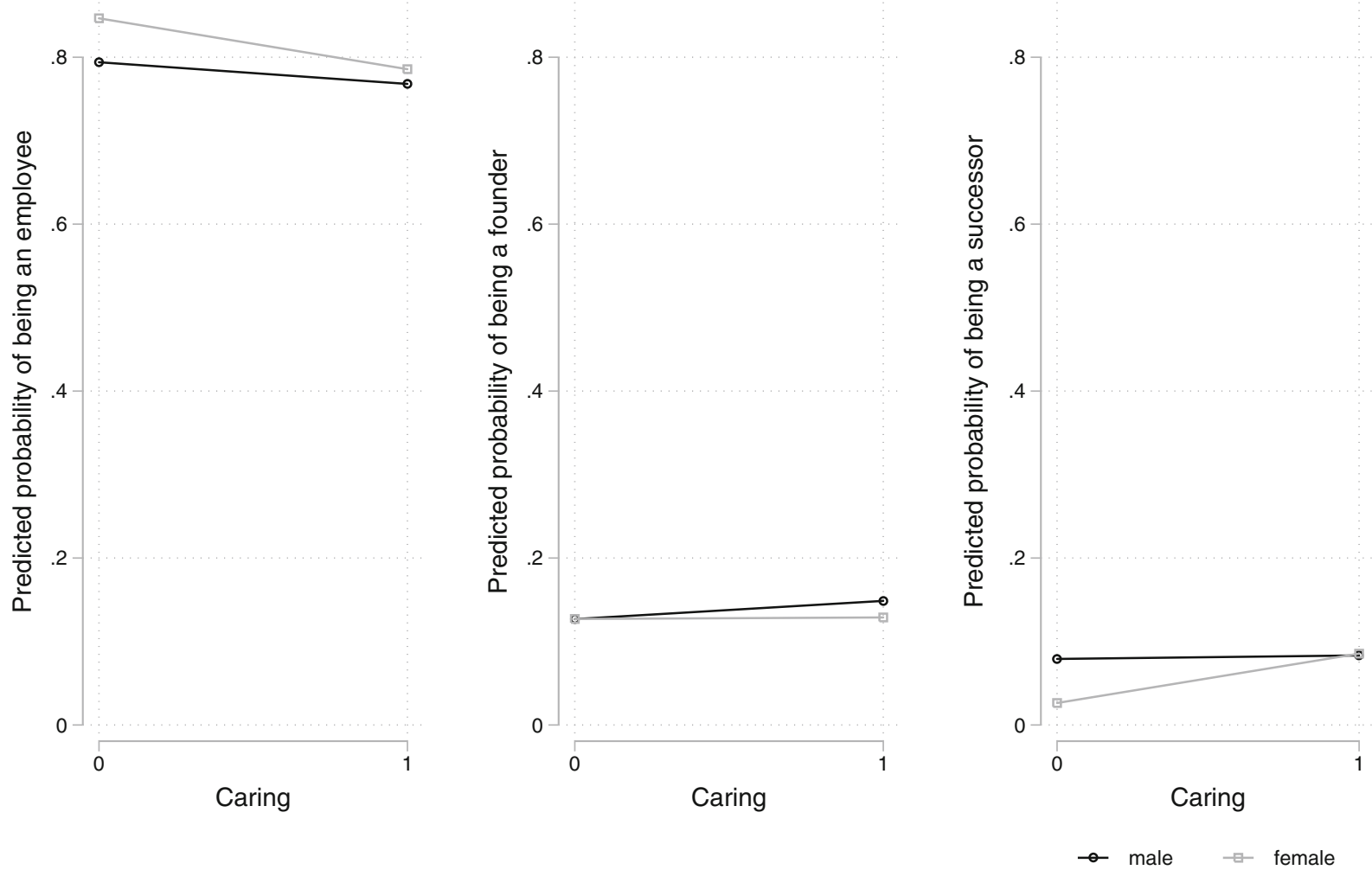

Fig. 1 Graph for H2: two-way interaction of gender and traditional gender norms on career status as dependent variable for the full sample 

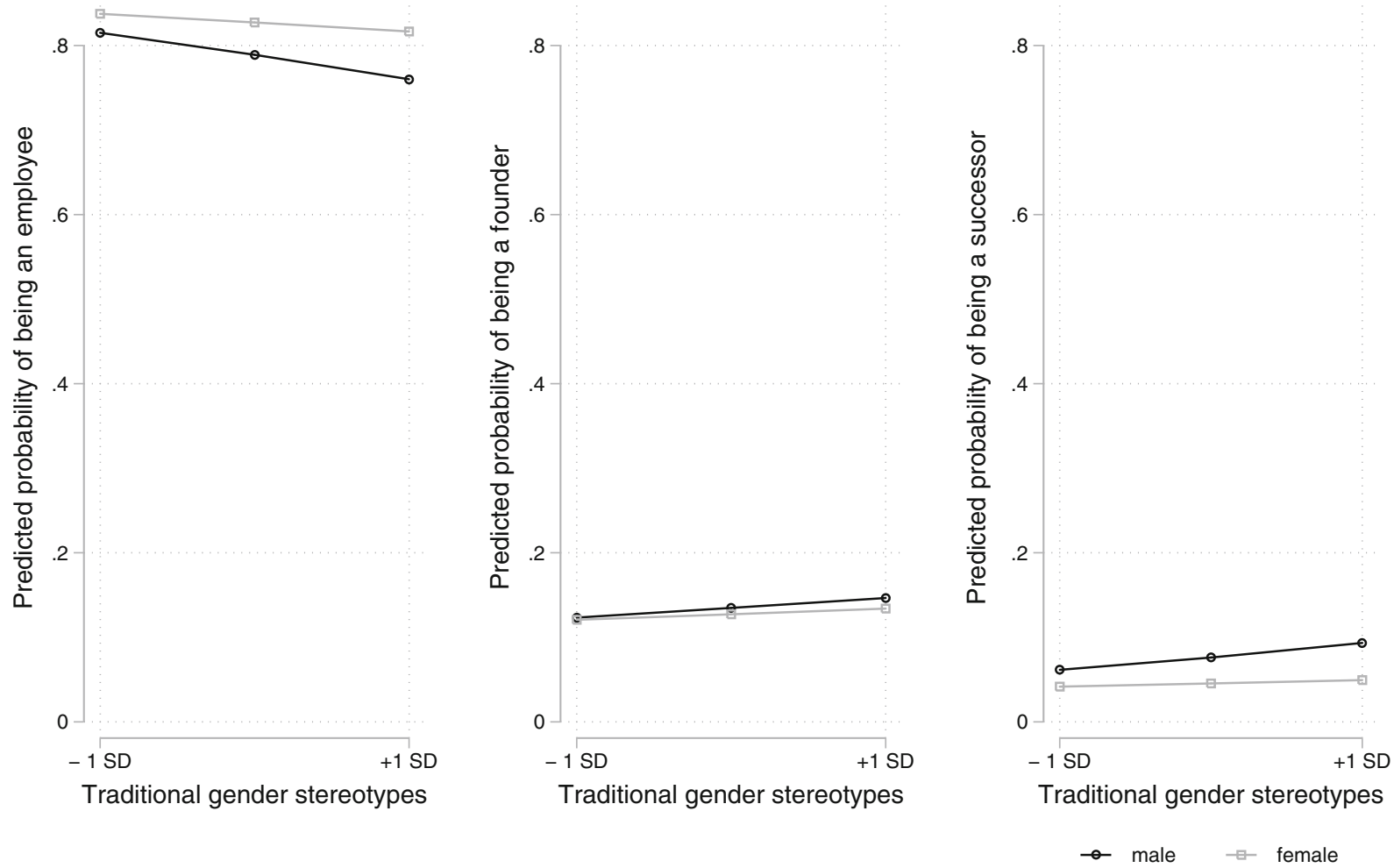

Fig. 2 Graph for H3: two-way interaction of gender and caring on career status as dependent variable for the full sample

\subsection{Summary of results}

Our results are summarised in Table 6. Most clearly supported are H1a, H3a and H3b, and H5a and H5b, with weaker support for H2a. In line with $\mathrm{H} 1 \mathrm{a}$, gender identity is associated with career status such that a woman is more likely than a man to be an employee than a successor to a family firm (H1a). Second, caring for a family member increases the probability that a woman will be a successor to a family firm rather than an employee or a founder (H3a and $\mathrm{H} 3 \mathrm{~b})$. While H2a provides weak support for the prediction that a woman's adherence to traditional gender norms even further increases the likelihood of being an employee vs. a successor, in the presence of a selfemployed mother (H5), the reverse is true, i.e. she is then more likely to be a successor than an employee or a founder (H5a and $\mathrm{H} 5 \mathrm{~b})$. The other hypotheses (H1b, $\mathrm{H} 2 \mathrm{~b}$, comparing gender identity's main effects and traditional gender norm's moderating effects on being a successor vs. founder) and H4 (two-way interaction effects of gender identity and having a self-employed mother) are not supported.

\section{Discussion}

\subsection{Theoretical contributions}

We make four key contributions with our research. First, by distinguishing between entry modes (starting one's own firm vs. joining the family firm), we develop a better view of the gender gap in entrepreneurship among young Europeans. Some of what has previously been considered a gender gap (Baughn et al. 2006; Jennings and Brush 2013; Lukeš et al. 2019) may be due to differences in family business succession, and not founding behaviour. Women are less often selfemployed than men, but the majority of this effect derives from the career choice of succession, not founding. Furthermore, traditional gender norms deter women from being self-employed but largely in the context of succession.

Second, our study underscores the relevance of the family embeddedness perspective (Aldrich and Cliff 2003) to women's entrepreneurship and gender research. By considering family relationships, we enhance our ability to make gender-related predictions of career 

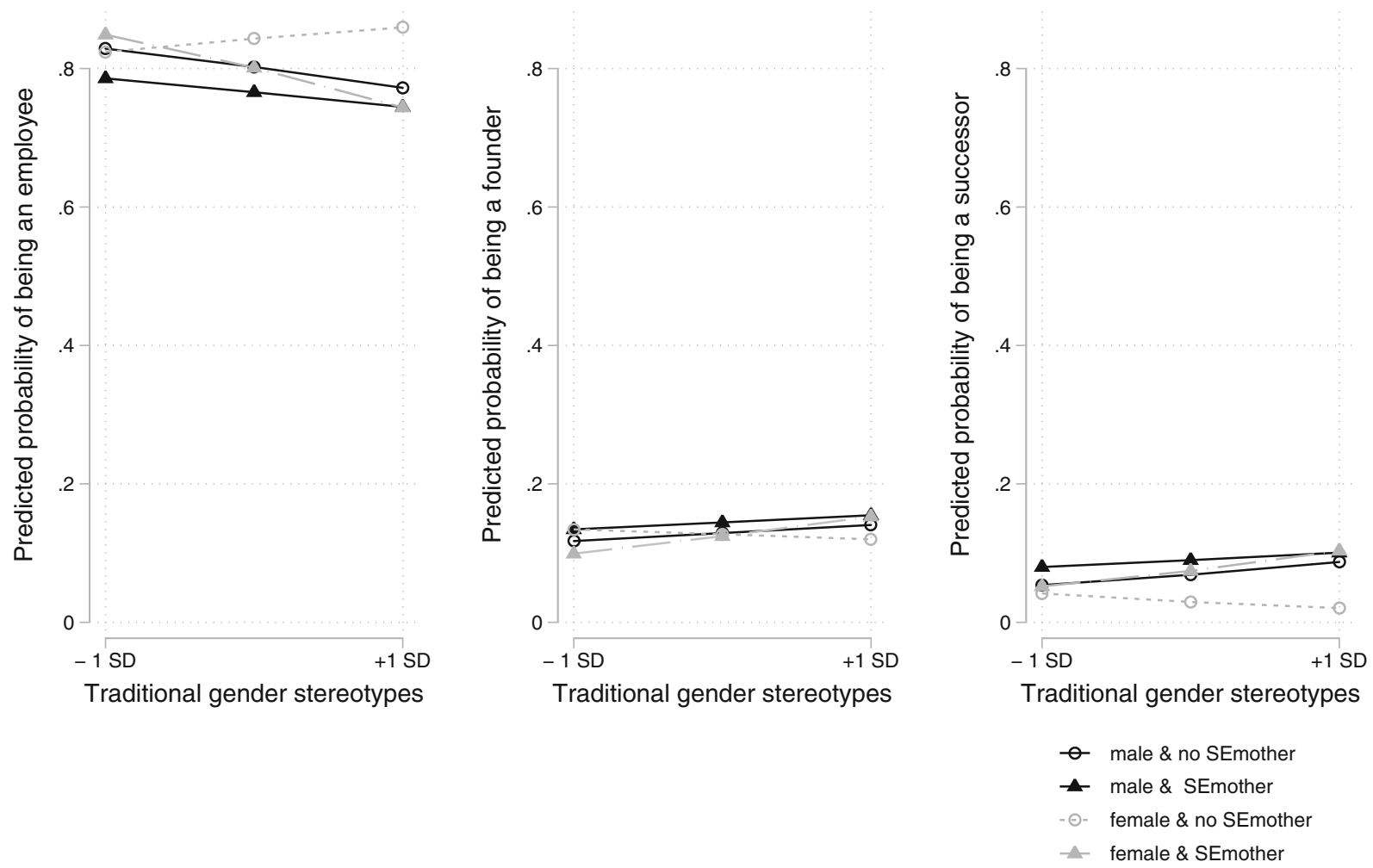

Fig. 3 Graph for H5: three-way interaction of gender, traditional gender norms and self-employed mother on career status as dependent variable for the full sample

choice. We further develop the conclusions of Noseleit (2014), suggesting that childcare may pull women into self-employment by showing that childcare pulls women mainly into succession but not founding. These findings suggest, thus, that it is the family business environment that best enables daughters to balance career with their childcare responsibilities.

Third, we enhance our understanding of the role of culture in occupational choice, building on the multilevel view of culture proposed by Leung et al. (2005) and Bullough et al. (2017b), especially when different aspects of that culture may seem to contradict one another or clash. Instead of family being subordinate to societal influences (cf. Welter et al. 2014), we see just the opposite. Family takes precedence when familial and societal norms contradict each other due to proximity, intensity, and longevity considerations. In line with Greene et al. (2013), having a self-employed mother as role model serves as a counter-stereotypical factor, thereby offsetting the otherwise negative effect that traditional gender norms can have on female participation in self-employment (Baughn et al. 2006). Thus, positive role models can change the way norms are acted out. Another explanation may be that selfemployed mothers tend to accept daughters as successors more often than self-employed fathers. Either way, we answer past calls to analyse mothers' influence on succession (Nelson and Constantinidis 2017).

Finally, our study is one of the first to verify the nature of the gender gap between family succession and other occupational choices for actual behaviour, vs. entrepreneurial intentions (Zellweger et al. 2011; Schröder et al. 2011). Longitudinal studies on nascent entrepreneurship confirm that a large proportion of nascent entrepreneurs do not go on to found a business (Lukeš and Zouhar 2016). Thus we contribute to past research by examining actual rather than intended career choice among young people.

\subsection{Implications for practitioners}

Regarding practical implications of our study, given the potential influence of traditional gender norms on career choice, especially family business-owning parents should monitor their own assumptions, in order to avoid overlooking the talented daughter to succeed in the 
Table 6 Summary of findings

\begin{tabular}{lll}
\hline Hypothesis & Full sample $(N=2897)$ & $\begin{array}{l}\text { Non-Turkish subsample } \\
(N=2396)\end{array}$ \\
\hline
\end{tabular}

H1: gender identity is associated with the career status of young people such that a woman is more likely than a man ...
H1a: ... to be an employee than a successor ${ }^{\mathrm{a}}$
Supported
Not supported
Not supported
H1b: ... to be a founder than a successor ${ }^{\mathrm{a}}$
Not supported

H2: Traditional gender norms moderate the relationship between gender identity and career status such that a woman who adheres more to traditional gender norms is even more likely than a woman who adheres less to traditional gender norms ...

H2a: ... to be an employee than a successor. ${ }^{\text {a }}$

$\mathrm{H} 2 \mathrm{~b}$ : ... to be a founder than a successor. ${ }^{\mathrm{a}}$

$\mathrm{H} 3$ : Caring responsibilities moderate the relationship between gender identity and career status such that a woman with caring responsibilities is more likely than a woman without caring responsibilities ...

H3a: to be a successor than an employee. ${ }^{b}$

H3b: to be a successor than a founder. ${ }^{\text {b }}$

H4: Having a self-employed mother moderates the relationship between gender identity and career status such that a woman with a self-employed mother is more likely than a woman without a self-employed mother ...

H4a: ...to be a successor than an employee. ${ }^{\text {b }}$

H4b: Having a self-employed mother moderates the relationship between gender identity and career status such that a woman with a self-employed mother is more likely than a woman without a self-employed mother to be a successor than a founder. ${ }^{\text {b }}$

H5: The moderating effect of traditional gender norms on the relationship between gender identity and career status predicted in hypothesis 2 will be reversed when the mother has been self-employed, such that a woman who adheres more to traditional gender norms is more likely than a woman who adheres less to traditional gender norms ...

H5a: ... to be a successor than an employee. ${ }^{\mathrm{b}}$

Supported

Supported
Supported (weakly)

Not supported

Supported

Supported

Not supported

Not supported
H5b: ... to be a successor than a founder. ${ }^{b}$
Supported (weakly)

Not supported

$T G N$, traditional gender norms

${ }^{a}$ Support requires a positive (interaction) coefficient in the logistic regression for employee/founder vs. successor, and/or in the case of an interaction, a positive average marginal effect (AME) for the employee/founder, and negative AME for successor, together with a graph consistent with the interaction

${ }^{\mathrm{b}}$ Support requires a negative (interaction) coefficient in the logistic regression for employee/founder vs. successor, and/or in the case of an interaction, a negative average marginal effect (AME) for the employee/founder, and positive AME for successor, together with a graph consistent with the predicted interaction

family business. Second, in order to encourage family business leadership among young women, in the absence of a self-employed mother, parents and other influential adults may seek ways to provide alternative female role models, e.g. with women in executive managerial positions in the company.

Lastly, the structure of the gender gap in our sample calls for better targeting in women's entrepreneurship programmes. If these programmes address young women comparable to those in our sample, policy makers should consider targeting succession-an alternative to founding a company-as an important career option. While traditional gender norms are clearly the largest challenge for women in this domain, programmes might also tackle the gap between male-dominated and female-dominated" industries, e.g. by fostering young 
women's interest in technical and science-related professions and careers.

\subsection{Limitations and directions for future research}

Regarding limitations, first, our large-scale survey includes several retrospective questions regarding parental self-employment and thus may contain a retrospective bias.

Second, we rely entirely on self-reporting questionnaires. However, in relation to both possible limitations, our variables have been measured by easy-to-answer questions that relate directly to the personal situation or perception of the individual, thus limiting potential bias. Moreover, our sample structure ensures that new venture creation and family business succession happened in the recent past; the median number of years spent in selfemployment in our sample is four.

Third, for the traditional gender norms construct we rely on an individual-level single-item measure. While the lack of a multi-item scale is an obvious methodological shortcoming, this approach provides the benefits of directly measuring an individual's perception of such norms. Moreover, the item we used is successfully used for measuring gender norms for more than three decades, e.g. as part of the International Social Survey Programme (Braun and Scott 2009). Gender norms at the national level, such as gender egalitarian norms and in-group collectivism norms (Bullough et al. 2017b), may shape parental support for a daughter's succession and independent venture creation. While we did not have enough countries to test for such effects adequately using multi-level analysis, future studies might explore the interplay of such norms.

Fourth, future research could develop a more sophisticated categorisation of self-employment to include those founding vs. purchasing a business, or employers vs. freelancers primarily working for themselves in the gig economy.

Finally, we recognise that our research is grounded in the more conventional view that every individual considers someone as a mother figure and someone as a father figure. Future research may also focus on divergent family structures with single or same-sex parents and their influences on entrepreneurial career choice.

\section{Conclusion}

To explore the question of gender in entrepreneurship, this paper adopts a multi-levelled view of culture including both societal gender norms and family embeddedness, to predict the career status of young Europeans. It shows that gender identity matters, but its consequences differ across different forms of selfemployment and individual circumstances.

We contribute to the literature on culture, gender, and entrepreneurship in several ways. First, we argue for the relevance of family considerations in career choice, expanding upon the family embeddedness perspective. Second, it is important to consider the different layers of culture, including the family and the societal level, and how they may interweave to influence an individual's behaviour. We show that the former, especially the selfemployed mother as role model, takes precedence over the latter if both give contrasting cues to the daughter in her career choices.

Empirically, we find strong differences between founders and successors - while the gender gap seems obvious in the case of succession, our data show no hint of a significant gender gap in young founders. Practically, these results suggest the need to make family business owners more aware of their own gender bias, which can limit the involvement of their daughters in the family business and also jeopardise their ability to consider all available candidates to take over the family firm. Our results also question whether young women are really underrepresented in the general entrepreneurial domain. They further suggest that the succession gender gap might be mitigated by self-employed mothers serving as positive role models and greater receptivity of combining work and family caregiving roles. It may also be mitigated by making young women aware of their own biases with respect to different career options. We hope that our findings and suggestions will motivate other researchers to further explore the interaction of family, gender, and culture in the domain of entrepreneurship.

Acknowledgements We gratefully acknowledge financial support by the project Cultural Pathways to Economic SelfSufficiency and Entrepreneurship (CUPESSE; Seventh Framework Programme, grant agreement Nr. 613257). We are also indebted to the three anonymous reviewers for their constructive feedback. Finally, this paper has benefited from presentations at the 18th European Academy of Management (EURAM) conference in Reykjavik and the 78th Academy of Management (AOM) conference in Chicago. 
Funding Open Access funding enabled and organized by Projekt DEAL. Grant Agreement No. 61325.

Data availability CUPESSE data available at https://dbk.gesis. org/dbksearch/sdesc2.asp $?$ no $=7475 \& \mathrm{db}=\mathrm{e} \& \mathrm{doi}=10.4232$ $/ 1.13042$

\section{Compliance with ethical standards}

Conflict of interest The authors declare that they have no conflict of interest.

Code availability Stata code available from corresponding author upon request.

Open Access This article is licensed under a Creative Commons Attribution 4.0 International License, which permits use, sharing, adaptation, distribution and reproduction in any medium or format, as long as you give appropriate credit to the original author(s) and the source, provide a link to the Creative Commons licence, and indicate if changes were made. The images or other third party material in this article are included in the article's Creative Commons licence, unless indicated otherwise in a credit line to the material. If material is not included in the article's Creative Commons licence and your intended use is not permitted by statutory regulation or exceeds the permitted use, you will need to obtain permission directly from the copyright holder. To view a copy of this licence, visit http://creativecommons.org/licenses/by/4.0/.

\section{References}

Ahl, H. (2006). Why research on women entrepreneurs needs new directions. Entrepreneurship Theory and Practice, 30(5), 595621. https://doi.org/10.1111/j.1540-6520.2006.00138.x.

Aldrich, H., \& Cliff, J. (2003). The pervasive effects of family on entrepreneurship: Toward a family embeddedness perspective. Journal of Business Venturing, 18(5), 573-596. https://doi.org/10.1016/S0883-9026(03)00011-9.

Azmat, F., \& Fujimoto, Y. (2016). Family embeddedness and entrepreneurship experience: A study of Indian migrant women entrepreneurs in Australia. Entrepreneurship \& Regional Development, 28(9-10), 630-656. https://doi. org/10.1080/08985626.2016.1208279.

Baughn, C. C., Chua, B., \& Neupert, K. E. (2006). The normative context for women's participation in entrepreneurship: A multicountry study. Entrepreneurship Theory and Practice, 30(5), 687-708. https://doi.org/10.1111/j.15406520.2006.00142.x.

Bloemen-Bekx, M., Voordeckers, W., Remery, C., \& Schippers, J. (2019). Following in parental footsteps? The influence of gender and learning experiences on entrepreneurial intentions. International Small Business Journal. https://doi. org/10.1177/0266242619838936.

Braun, M., \& Scott, J. (2009). Changing public views of gender roles in seven nations, 1988-2002. In M. Haller, R. Jowell, \&
T. W. Smith (Eds.), The international social survey programme, 1984-2009: Charting the globe (pp. 358-377). London: Routledge.

Bullough, A., Moore, F., \& Kalafatoglu, T. (2017a). Research on women in international business and management: Then, now, and next. Cross Cultural \& Strategic Management, 24(2), 211230. https://doi.org/10.1108/CCSM-02-2017-0011.

Bullough, A., Renko, M., \& Abdelzaher, D. (2017b). Women's business ownership: Operating within the context of institutional and in-group collectivism. Journal of Management, 43(7), 2037-2064.

Campopiano, G., De Massis, A., Rinaldi, F. R., \& Sciascia, S. (2017). Women's involvement in family firms: Progress and challenges for future research. Journal of Family Business Strategy, 8(4), 200-212. https://doi.org/10.1016/j. jfbs.2017.09.001.

Diamond, M. (2002). Sex and gender are different: Sexual identity and gender identity are different. Clinical Child Psychology and Psychiatry, 7(3), 320-334.

Elam, A., \& Terjesen, S. (2010). Gendered institutions and crossnational patterns of business creation for men and women. The European Journal of Development Research, 22(3), 331-348. https://doi.org/10.1057/ejdr.2010.19.

Greene, F. J., Han, L., \& Marlow, S. (2013). Like mother, like daughter? Analyzing maternal influences upon women's entrepreneurial propensity. Entrepreneurship Theory and Practice, 37(4), 687-711. https://doi.org/10.1111/j.15406520.2011.00484.x.

Hair, J. F., Black, W. C., Babin, B. J., \& Anderson, R. E. (Eds.). (2010). Multivariate data analysis (7th ed.). Upper Saddle River: Pearson Prentice Hall.

Hoffmann, A., Junge, M., \& Malchow-Møller, N. (2015). Running in the family: Parental role models in entrepreneurship. Small Business Economics, 44(1), 79-104. https://doi. org/10.1007/s11187-014-9586-0.

House, R., Javidan, M., Hanges, P., \& Dorfman, P. (2002). Understanding cultures and implicit leadership theories across the globe: An introduction to project GLOBE. Journal of World Business, 37(1), 3-10. https://doi. org/10.1016/S1090-9516(01)00069-4.

Hytti, U., Alsos, G. A., Heinonen, J., \& Ljunggren, E. (2016). Navigating the family business: A gendered analysis of identity construction of daughters. International Small Business Journal, 35(6), 665-686. https://doi.org/10.1177 /0266242616675924.

Jennings, J. E., \& Brush, C. G. (2013). Research on women entrepreneurs: Challenges to (and from) the broader entrepreneurship literature? Academy of Management Annals, 7 (1), 663-715. https://doi.org/10.1080 /19416520.2013.782190.

Karaca-Mandic, P., Norton, E. C., \& Dowd, B. (2012). Interaction terms in nonlinear models. Health Services Research, 47(1pt1), 255-274. https://doi.org/10.1111/j.14756773.2011.01314.x.

Karataş-Özkan, M., Erdoğan, A., \& Nicolopoulou, K. (2011). Women in Turkish family businesses: Drivers, contributions and challenges. International Journal of Cross Cultural Management, 11(2), 203-219. https://doi.org/10.1177 $/ 1470595811399189$. 
Kubíček, A., \& Machek, O. (2019). Gender-related factors in family business succession: a systematic literature review. Review of Managerial Science, 13(5), 963-1002.

Leung, K., Bhagat, R. S., Buchan, N. R., Erez, M., \& Gibson, C. B. (2005). Culture and international business: Recent advances and their implications for future research. Journal of International Business Studies, 36(4), 357-378. https://doi. org/10.1057/palgrave.jibs.8400150.

Lindquist, M., Sol, J., \& van Praag, M. (2015). Why do entrepreneurial parents have entrepreneurial children? Journal of Labor Economics, 33(2), 269-296. https://doi.org/10.1086 1678493.

Lukeš, M., \& Zouhar, J. (2016). The causes of early-stage entrepreneurial discontinuance. Prague Economic Papers, 25(1), 19-36. https://doi.org/10.18267/j.pep.534.

Lukeš, M., Feldmann, M., \& Vegetti, F. (2019). Work values and the value of work: Different implications for young adults' self-employment in Europe. The ANNALS of the American Academy of Political and Social Science, 682(1), 156-171. https://doi.org/10.1177/0002716219828976.

Markussen, S., \& Røed, K. (2017). The gender gap in entrepreneurship-the role of peer effects. Journal of Economic Behavior \& Organization, 134, 356-373. https://doi.org/10.1016/j.jebo.2016.12.013.

Marlow, S., \& Martinez Dy, A. (2018). Annual review article: Is it time to rethink the gender agenda in entrepreneurship research? International Small Business Journal, 36(1), 3-22. https://doi.org/10.1177/0266242617738321.

Marlow, S., \& McAdam, M. (2013). Gender and entrepreneurship: Advancing debate and challenging myths; exploring the mystery of the under-performing female entrepreneur. International Journal of Entrepreneurial Behavior \& Research, 19(1), 114-124. https://doi.org/10.1108 /13552551311299288.

Nelson, T., \& Constantinidis, C. (2017). Sex and gender in family business succession research: A review and forward agenda from a social construction perspective. Family Business Review, 30(3), 219-241. https://doi.org/10.1177 /0894486517715390.

Norton, E. C., Wang, H., \& Ai, C. (2004). Computing interaction effects and standard errors in logit and probit models. The Stata Journal, 4(2), 154-167. https://doi.org/10.1177 /1536867X0400400206.

Noseleit, F. (2014). Female self-employment and children. Small Business Economics, 43(3), 549-569. https://doi. org/10.1007/s11187-014-9570-8.
Overbeke, K. K., Bilimoria, D., \& Perelli, S. (2013). The dearth of daughter successors in family businesses: Gendered norms, blindness to possibility, and invisibility. Journal of Family Business Strategy, 4(3), 201-212. https://doi.org/10.1016/j. jfbs.2013.07.002.

Pearse, R., \& Connell, R. (2016). Gender norms and the economy: Insights from social research. Feminist Economics, 22(1), 30-53. https://doi.org/10.1080/13545701.2015.1078485.

Plummer, L. A., Allison, T. H., \& Connelly, B. L. (2016). Better together? Signaling interactions in new venture pursuit of initial external capital. Academy of Management Journal, 59(5), 1585-1604. https://doi.org/10.5465/amj.2013.0100.

Rothausen, T. J. (2009). Management work-Family research and work - Family fit: Implications for building family Capital in Family Business. Family Business Review, 22(3), 220-234. https://doi.org/10.1177/0894486509337409.

Schröder, E., Schmitt-Rodermund, E., \& Arnaud, N. (2011). Career choice intentions of adolescents with a family business background. Family Business Review, 24(4), 305-321. https://doi.org/10.1177/0894486511416977.

Storey, D. J., \& Greene, F. J. (2010). Small business and entrepreneurship. Harlow: Financial Times/Prentice Hall.

Tosun, J. J., Arco-Tirado, J. L., Caserta, M. et al. (2019). Perceived economic self-sufficiency: A country-and generation-comparative approach. European Political Science, 18, 510531. https://doi.org/10.1057/s41304-018-0186-3.

Wellington, A. J. (2006). Self-employment: The new solution for balancing family and career? Labour Economics, 13(3), 357386. https://doi.org/10.1016/j.labeco.2004.10.005.

Welter, F., Brush, C., \& De Bruin, A. (2014). The gendering of entrepreneurship context. Institut für Mittelstandsforschung Bonn (Hrsg.): Working Paper, 1/14. https://doi.org/10.2139 /ssrn.2557272.

Williams, R. (2012). Using the margins command to estimate and interpret adjusted predictions and marginal effects. The Stata Journal, 12(2), 308-331. https://doi.org/10.1177/1536867 X1201200209.

Zellweger, T., Sieger, P., \& Halter, F. (2011). Should I stay or should I go? Career choice intentions of students with family business background. Journal of Business Venturing, 26(5), 521-536. https://doi.org/10.1016/j.jbusvent.2010.04.001.

Publisher's note Springer Nature remains neutral with regard to jurisdictional claims in published maps and institutional affiliations. 